\title{
Estimation of dietary intake of melanoidins from coffee and bread
}

\author{
Vincenzo Fogliano (a) and Francisco J. Morales* (b)
}

DOI: 10.1039/c0fo00I56b

\begin{abstract}
Melanoidins are defined as polymeric high molecular weight, brown-coloured Maillard reaction endproducts, containing nitrogen. They escape digestion and pass through the upper gastrointestinal tract and can interact with the different microbial species present in the colon. Major dietary sources of melanoidins are coffee and bread crust. Both coffee and bread crust melanoidins can be fermented by the human hindgut microflora thus sharing some of the properties attributed to dietary fibre. Despite the emerging positive physiological properties of such dietary constituents their intake has not been estimated yet. To this aim melanoidin content in different type of coffee brews, bread and dry biscuits was determined by sequential ultrafiltration and enzymatic digestion. Despite some drawbacks and limiting steps in the calculation, such as the lack of a reference material, an educated guess on the dietary intake of melanoidins has been put forward. Data indicated that the intake of coffee melanoidins ranged between 0.5 to $2.0 \mathrm{~g}$ per day for moderate and heavy consumers, respectively. For bread and dry biscuits an intake in the ranges of $1.8-15.0$ and 3.2-8.5 g per day has been calculated. These figures suggest that a realistic estimation of melanoidins dietary intake for general population would be close to I0 g per day considering all the possible alimentary sources.
\end{abstract}

A Dipartimento di Scienza degli Alimenti University of Napoli “Federico II”, via Universita I00, 80055 Portici, Italy

B Instituto de Ciencia y Tecnología de Alimentos y Nutrición-ICTAN, Consejo Superior de Investigaciones Científicas (CSIC), José Antonio Novais 10, 28040 Madrid, Spain. E-mail: fjmorales@if.csic.es; Fax: +34 9l 549 3627; Tel: +34 915492300

\section{Introduction}

Melanoidins are widely distributed in thermally processed food and they are defined as polymeric high molecular weight, brown coloured Maillard reaction (MR) end-products, containing nitrogen.I,2 Their chemical structure is complex and still remains largely unknown.3-6 However, four main proposals of the structure have been put forward: (i) low-molecular weight coloured substances crosslinked to free amino groups of lysine or arginine in proteins,7 (ii) units of furan and/or pyrroles that, through polycondensation reactions, form melanoidin repeating units, 8 (iii) skeleton mainly built up from sugar degradation products formed in the early stages of the $M R$, polymerized and linked by amino compounds,5 (iv) skeleton mainly built up form proteins crosslinked by MR products (i.e. the melanoproteins). 9

The absence of a known molecular structure and the strict dependence of its concentration on processing conditions in the final products have hampered an estimation of the dietary intake of melanoidins thus far. However, mounting evidence suggests that melanoidins are not an inert material and they can exert some physiological action.

The main sources of dietary melanoidins are definitely coffee and bakery products; however other processed foods such as cocoa, 9 malt, I 0 roasted barley, I I black beer, I 2 roasted potatoes, I 3 roasted 
pulses and seeds, 14 meat 15 soy sauces, 16 balsamic vinegar, 17 sweet wine, 18 processed tomatoes, 19 also contain melanoidins. Besides being the main dietary source, coffee and bread melanoidins are also representative of the two main typologies of melanoidins. The principal constituent of coffee melanoidins is polysaccharides. However, in bread the main structure is a proteinaceous material and these melanoidins are referred to as melanoproteins as well.9,20

During the roasting of coffee green beans chemical and structural changes taken place where polysaccharides, galactomannan-like and arabinogalactan-like carbohydrates,6,2।,22 proteins,23,24 and phenolic compounds, mainly hydroxycinnamates, 2,25-29 contribute to the formation of coffee melanoidins. 30 Recently, it was also demonstrated that phenolic compounds can also be non-covalently linked to coffee melanoidins and melanoidins could acts as carriers of low molecular weight substances.31

In bakery products melanoidins are formed by gluten proteins cross-linked by coloured Maillard Reaction Products (MRPs),32 while other small molecular weight coloured MR products are entrapped in the gluten network.20 Melanoidins are present only in the crusts and can be considerably enhanced by the use of a browning agent that can be added on the surface of the dough. Bread melanoidins concentration depends on the intensity of the thermal input: the higher the treatment the higher the concentration. Bread melanoidins are mainly water insoluble therefore they can be efficiently extracted only after extensive enzymatic digestion.33

Melanoidins, and coffee melanoidins in particular, have different functional properties apart from their contribution to colour and technological properties, being able to bind flavours, 34 exerting antioxidant capacity to foods 31 and suppressing oxidative stress in cells,35 metal-chelating properties,36 antimicrobial activity,37 suppressing Helicobacter pylori adhesion, 38 modulating chemopreventive enzymes,39 among others.

In the last ten years many studies suggested that they can have a relevant role in the gastrointestinal tract since melanoidins are fermented in the colon, and act as dietary fibre, modulating their bacterial population.33,40-42 Recently, Alexander43 in the base on previous knowledge stated that melanoidins should be considered as antioxidant dietary fibre 44,45 which play a role in the prevention of cardiovascular disease and control of colorectal cancer.46 This statement is strengthened by the observation that a coffee melanoidin-rich ingredient, the coffee silverskin, is able to promote Bifidobacteria growth, 47 and by the fact that the degradability of the carbohydrate part of the coffee brew melanoidins by human faecal microbiota was demonstrated.48 On the other hand it should be considered that most of the melanoidins are recovered in the faeces 39 and that faecal antioxidant activity showed a direct correlation with coffee intake. 49

Despite the emerging physiological role highlighted for food melanoidins, their dietary intake has never been calculated. This consideration prompted us to provide an educated guess on the dietary intake of melanoidins from two major sources, coffee and bakery products. Data on the amount of melanoidins in processed foods represent an essential pre-requisite to put in the appropriate context their possible role as dietary fibre. The estimation of melanoidin dietary intake will be of interest to assess the relationship between consumption patterns and epidemiological studies due to the relevance of melanoidins for gastrointestinal health.

\section{Methods}

Isolation of coffee melanoidins

Roasted coffee beans (Coffea arabica) samples were obtained from local stores. Roasted coffee beans were ground on a $0.43 \mathrm{~mm}$ mesh. Italian (moka coffee pot), filter (drop electric coffeemaker) and 
espresso (food service industry coffee maker) procedures were applied for coffee brew preparation as described by Sanchez-Gonzalez et al.50 Isolation of coffee melanoidins was as described by Borrelli et al.28 and Delgado-Andrade and Morales.3 I Briefly, the coffee brew (7 g coffee per $100 \mathrm{~mL}$ water) was filtered (Whatman Filter Paper number 40, ashless, Whatman, U.K.) and defatted with dichloromethane $(2 \times 200 \mathrm{~mL})$. The coffee brew was then subjected to ultrafiltration using an Amicon ultrafiltration cell model 8400 (Amicon, Beverly, MA), equipped with a $10 \mathrm{kDa}$ nominal molecular mass cut-off membrane. The retentate was filled up to $200 \mathrm{~mL}$ with water and washed again. This washing procedure was repeated at least 3 times. The high-molecular-weight (HMW) fraction was freeze-dried and stored in a desiccator at $4{ }^{\circ} \mathrm{C}$ until analysis. The melanoidins content ( $\mathrm{g}$ per $100 \mathrm{~g}$ coffee) was determined by the weight of the freeze-dried product after ultrafiltration.

Isolation of biscuits melanoidins by sequential ultrafiltration Biscuit melanoidins were prepared in a similar way than coffee ones, although a sample solubilization was carried out as described by Borrelli and Fogliano33 with some modifications as described by Martín et al.5I Briefly, homogenized biscuit samples $(500 \mathrm{mg}$ ) were diluted in $25 \mathrm{~mL}$ of a Pronase E solution containing $0.375 \mathrm{mg}$ of Pronase E (7.5 units $\mathrm{mg}$ I, Sigma- Aldrich) in $0.1 \mathrm{M}$ sodium-borate at $\mathrm{pH} 8.2$ buffer, vigorously stirred, and incubated at $37^{\circ} \mathrm{C}$ for $40 \mathrm{~h}$ under shaking. The reaction was stopped by cooling in an ice-water bath followed by addition of $100 \mathrm{~mL}$ of trichloroacetic acid solution $(40 \%, \mathrm{w} / \mathrm{v})$ and centrifugation at $4500 \mathrm{~g}$ for $10 \mathrm{~min}$ at

4 C. At the end of each enzymatic digestion, samples were dialysed using a membrane with a nominal molecular weight "cut-off" of $3000 \mathrm{Da}$. The melanoidins content (g per $100 \mathrm{~g}$ biscuit) was determined by the weight of the freeze-dried product after ultrafiltration.

Isolation of melanoidins from bread crust.

Bread crust was obtained from commercial sliced bread and baguettes. Sourdough loaves were pieces of I kg obtained by sour dough fermentation and cooked at $220 \quad \mathrm{C}$ for $90 \mathrm{~min}$. The bread crust was separated from the crumb with a kitchen knife than it was freeze-dried and ground in a mill. Samples were enzymatically digested by adding $3 \mathrm{ml}$ of $20 \mathrm{mM}$ Tris- $\mathrm{HCl}$ buffer $(\mathrm{pH} 1 / 48)$, containing $0.1 \mathrm{mg}$ $\mathrm{mL}$ I of Pronase E (7.5 U mg I, Sigma- Aldrich), to $250 \mathrm{mg}$ of the samples, and after a vigorous mixing the samples were incubated at $37^{\circ} \mathrm{C}$ for different periods (up to 7 days). The reaction was stopped by cooling in an ice-water bath followed by addition on $100 \mathrm{~mL}$ of trichloroacetic acid solution $(40 \%, w / v)$ and centrifugation at $4500 \mathrm{~g}$ for $10 \mathrm{~min}$ at $4 \quad$ C. At the end of each enzymatic digestion, samples were dialysed using a membrane with a nominal molecular weight "cut-off" of $3000 \mathrm{Da}$. The melanoidins content ( $\mathrm{g} / \mathrm{l} 00 \mathrm{~g}$ bread) was determined by the weight of the freeze-dried product after ultrafiltration.

Consumption databases.

Dietary intake of melanoidins from coffee and bread were taken from different food consumption databases. Data from coffee consumption were taken from an exposure study carried out from the latest worldwide coffee consumption in 2007 as provided by the Spanish Federation of Coffee;52 those for bread and dry biscuits were taken from the database of Italian consumption (INRAN). An average body weight (bw) of $70 \mathrm{~kg}$ was used to estimate the total daily intake of melanoidins to total population and expressed as $\mathrm{mg} \mathrm{kg(bw)} \mathrm{I} \mathrm{day} \mathrm{I.}$

\section{Results and discussion}

Estimation of dietary intake of coffee melanoidins

Coffee is one of the most popular beverages around the world as about 400000 million cups of coffee are consumed every year. The amount of melanoidin in the cup varies with the coffee roasting and 
coffee brew preparation. To date, there is no evidence about the contribution of the coffee variety (arabica or robusta) on the occurrence of melanoidin regardless the roasting process applied. It is known that the darker the roasting degree, the higher the amount of melanoidins and their complexity will vary with the degree of roast.28 Type of extraction, strength of the brew (the higher the ratio powder/water the higher themelanoidins amount), pressure and serving size (extracting the same amount of powder with more water increases the amount of melanoidins) influence the final melanoidin intake from a cup of coffee.

To ascertain the effect of the extraction type, the overall extraction yield achievable with four coffee brew preparations is listed in Table I. These values have been obtained using always the same amount of coffee powder, while in the daily consumption an important role is played by the powder/water ratio used for the extraction. Obviously, for soluble coffee the yield is near the $100 \%$ and in this case the only variable to take into consideration is the amount of coffee powder per serving.

The bottleneck of melanoidins quantitation is the lack of a validated and well-established procedure to calculate its content. In addition, a standard reference material for such a purpose or even common procedures for isolation of melanoidins are not available which make the goal very challenging. In this respect, a step forward was done by COST Action 91953 that proposed a reference melanoidin derived from a glucose-glycine model system to unify further investigation on the structural and functional characteristics of food melanoidins. Unfortunately, the composition of coffee beans is far more complex than a single model system of sugar and amino acid, so only references specifically dealing with the isolation of coffee melanoidins have been used in this estimation. Three main approaches for isolation of coffee melanoidins from the coffee brew are described in the literature. The most extended one is based in the high molecular weight of these polymeric structures by applying dialysis tubing, ultrafiltration with $10 \mathrm{kDa}$ cut-off membranes (tangential flow, static-cells, centrifugation devices), and column gel-permeation for molecular exclusion separation of melanoidins and subsequent gravimetric estimation.2 Two more rapid procedures based on the colour potency of MRPs, 7 or by measuring the absorption at wavelengths or extinctions coefficients higher than $400 \mathrm{~nm} 54$ have been also proposed. There are some discrepancies among authors on the yield reached for each isolation procedure since, as suggested by Hofmann,55 low molecular coffee compounds might react during dialysis yielding higher molecular weight structures and increasing the final melanoidin content. This fact has recently been demonstrated by Bekedam et al.2 On the other hand, the application of gel permeation chromatography (e.g. Shephadex G-25) could underestimate the levels of melanoidin due to dead volume and the low amount of sample analysed which it is inherent to the technique.

Table 2 summarized the information of coffee melanoidins published thus far. When available, only values from medium roasted coffee beans were used to avoid the dependence of melanoidins levels with the degree of roasting. Since filtered coffee has been the major source for the preparation of coffee melanoidins in scientific literature, further calculations will be related to this coffee brew preparation. All in all, a mean melanoidins content of $7.2 \mathrm{~g}$ per $100 \mathrm{~g}$ of roasted coffee was obtained with a standard deviation of $2.97 \mathrm{~g}$ per $100 \mathrm{~g}(\min 1 / 436, \max 1 / 4$ II 5$)$.

Combining these data with those of Table I, determined that the amount of melanoidins in the brew is much higher in espresso coffee as it is more concentrated. As far as the soluble coffee is concerned, the higher amount of melanoidins depends on the peculiar process which is able to solubilise polysaccharides which usually remained unsolubilised.

Melanoidins content per serving cup of coffee is summarised in Table 3. The data take into account the average melanoidin content in medium roasted coffee $(7.2 \mathrm{~g}$ per $100 \mathrm{~g})$, the usual serving size for each coffee preparation and the proportion of coffee : - water used for the extraction. These data are further used to calculate the dietary intake of melanoidins taking into account the data of consumption for 
different countries. These data are not always available, clear and in some cases they are simply based on the data of roasted coffee sold in the country, but are useful as an approximation. In addition, the variability among coffee drinkers should be considered as well and will be another source of variation. Low, moderate and heavy coffee drinkers were classified as the consumers of 2, 4, and 6 coffee cups per day, respectively.56 From this data it can be derived that the intake of coffee melanoidins is in the order of magnitude of $\mathrm{I} g$ of coffee melanoidins per day reaching a peak of $2 \mathrm{~g}$ per day for the heavy drinkers. Obviously, dietary intake of coffee melanoidins is related to the habit of consumption both modality of brew preparation and the number of cups per day. Fig. I depicted the estimated dietary intake of melanoidins in basis of the 2007 worldwide databases of coffee consumption. Estimation of coffee melanoidins intake was calculated by combining the mean level of consumption in each country with a weighed estimation of coffee melanoidins content in filtered coffee. Data of melanoidins were extrapolated to a coffee brew preparation by filtering since it is not possible to ascertain the type of coffee brew preparation chosen by citizens in any database. Results showed a range of melanoidin intake between $200 \mathrm{mg}$ to $2600 \mathrm{mg}$ per capita per day which is in good agreement with the values calculated taking into account the daily cup consumption. It is worth noting that Scandinavian countries reached levels higher than 2 grams of coffee melanoidins per capita per day, although the higher intake was estimated for Luxemburg. Taking into consideration the population, values estimated for the European Union (984mg coffee melanoidins per capita per day, $14.1 \mathrm{mg}$ coffee melanoidins per $\mathrm{kg}(\mathrm{bw})$ per day) and United States of America (807 mg coffee melanoidins per capita per day, $11.5 \mathrm{mg}$ coffee melanoidins per $\mathrm{kg}(\mathrm{bw})$ per day), it can be concluded that the estimated worldwide intake of coffee melanoidins is about $900 \mathrm{mg}$ per capita per day. But those levels could be much higher for heavy coffee drinkers and for soluble coffee drinkers. Heavy coffee drinkers can easily reach more than $5 \mathrm{~g}$ per day of coffee melanoidins intake.

In summary, data from the worldwide coffee consumption57 are depicted in Table 4. Interestingly, similar results can be obtained considering the data of green coffee consumption in each country. For the higher coffee consumption an intake of about $2.0 \mathrm{~g}$ per day can be calculated considering $80 \%$ of consumers among adults and calculating a 17\% water loss during roasting and an average presence of 7.2 $\mathrm{mg}$ of melanoidins per $100 \mathrm{~g}$ of coffee.

\section{Estimation of dietary intake of bread crust melanoidins}

All bakery products contain a relevant part of melanoidins as can be appreciated by simply considering the amount of brown material present on the surface. In this paper bread and biscuits, representing a significant fraction of the intake of all bakery products, have been considered to perform an estimation of melanoidins intake. In bread, melanoidins are mostly present in the crust; while in dry biscuits they are homogeneously distributed in the products.

In comparison with coffee, the calculation of dietary melanoidins in bread is complicated by the poor water extractability of bread and biscuit melanoidins. In this work, it was decided to consider the soluble high molecular weight fraction remaining after in vitro starch and protein hydrolysis by a cocktail of enzymes resembling those acting in the human gastro intestinal tract. Different approaches have been proposed in the literature based on the use of various proteases and digestion protocols.58 Enzymatic digestion of the bread crust allows about $50 \%$ of the crust to solubilise and a significant part of this material is constituted by high molecular weight material (i.e. retained in a dialysis tube, not passing through membranes at different cut-offs by centrifugation or eluted in the first peak using gel filtration columns).

In Table 5 the amount of melanoidins recovered in different kinds of bread and biscuits using the enzymatic digestion protocol followed by the dialysis procedure as described in the method session are reported. In this work only common wheat, which is the most common grain used for the manufacture 
of bread was considered, no data are available about the role of type of cereal flour (wheat, rye, oat, barley, rice) to the formation of the crust or even of the melanoidins content. The percentage weight of the crust in the considered bread samples ranged from $35 \%$ for a baguette to $8 \%$ for the sliced bread. This interval can be representative of most of the commercial bread typologies present in the Western markets. Data reported in Table 5 showed that the amount of melanoidins in the bread crusts ranges between 30 to $14 \mathrm{~g}$ per $100 \mathrm{~g}$ of crust for sourdough loaves and baguette bread, respectively. These data are in agreement with previous observation on bread33,58 and in line with values reported for other similar bakery products.5 1,59 The amount of melanoidins found in dry biscuits was $12 \mathrm{~g}$ per $100 \mathrm{~g}$ of whole product and this is also in agreement with the previous observation from Martin et al.5I An amount of about $4.5 \mathrm{~g}$ can be obtained summing the fractions at high molecular weight obtained by gel filtration by these authors; this value is lower than the $12 \mathrm{~g}$ found in this work, however it is expected that dialysis provide a higher amount of melanoidins than gel filtration. Concentration of melanoidins in the same order of magnitude was also found in different bakery products, such as Spanish muffins59 where about $14 \mathrm{~g}$ of melanoidins per $100 \mathrm{~g}$ of whole product was reported.

To provide the estimation of melanoidin dietary intake, data for bread and biscuit consumption should be taken into account and they are also very heterogeneous among countries. Considering the data calculated on the basis of the wheat flour market, the consumption of bread in Western countries is in the range of 4I-303 kg per year per capita,60 that means II 2-830 g day per capita. However, starting from the flour market is not a reliable approach as it can be used for many purposes and the waste of bread (manufactured but not consumed) is very high; on the other hand a precise estimation can be obtained by a food consumption survey using individual questionnaires about dietary habits. A very recent one was published by the National Institute of Nutrition - INRAN6I and it reported that the average bread consumption among Italian bread consumers is $112 \mathrm{~g}$ per day while the $95^{\text {th }}$ percentile has a daily intake of $250 \mathrm{~g}$. The same survey found for biscuits an average intake of $27 \mathrm{~g}$ and $71 \mathrm{~g}$ for $95^{\text {th }}$ percentile. This data are in agreement with those reported in Spain.62 Average bread intake was of 112 $\mathrm{g}$ per day while sweet cookie consumption was $21.2 \mathrm{~g}$ per day. Similar data also come from the Swiss Federal Office for Agriculture showed in the years 1998 to 2007 a constant intake of $130 \mathrm{~g}$ of bread and $18 \mathrm{~g}$ of biscuits per day (www.blw.admin.ch/index.html?lang $1 / 4 \mathrm{en}$ ). Therefore for further calculation these data were used as it can be considered representative of general consumption at least in Western countries.

Combining the consumption data with the content of melanoidins in bread and biscuits reported in Table 5 the dietary intake of melanoidins from bread and biscuits have been calculated and the results are shown in Table 6. The calculation was made with the approximation that consumers always eat the same type of bread. So a subject consuming an average amount of sliced bread (i.e. $112 \mathrm{~g}$ per day) will have an intake of $1.6 \mathrm{~g}$ of melanoidins, while a subjects consuming $250 \mathrm{~g}$ of sourdough loaves $\left(95^{\text {th }}\right.$ percentile) have a daily intake of $15 \mathrm{~g}$ of melanoidins.

All in all, it can be concluded that, considering a mixed consumption of different types of bread and biscuits, a reasonable estimation of the intake of melanoidins is around 6-7 $\mathrm{g}$ per day for average consumers and 12-15 g per day for the 95th percentile. The educated guess performed in this paper demonstrated that it is possible to make a reliable estimation of the dietary intake of melanoidins from coffee and bread, which is of 1.5 and $6 \mathrm{~g}$, respectively for average consumers and can be roughly double for high consumers of these foods.

It is known that melanoidins escape digestion and pass through the upper gastrointestinal tract and then can interact with the different microbial species present in the hindgut.63 Specific evidence showing that both coffee and bread crust melanoidins can be metabolized/fermented by the human hindgut microflora selectively enhancing the growth of desirable bacteria in the gut has been demonstrated (all references above). Moreover, melanoidins have been demonstrated to develop antimicrobial activity 37 which could 
complement the prebiotic effect if this inhibition of the bacterial growth could be exerted over pathogenic bacteria.

Melanoidins share some of the properties attributed to dietary fibre. Similarly to dietary fibre they can differ in water holding capacity, viscous properties, solubility, antioxidant capacity and fermentability. All these aspects are worth investigating also for melanoidins considering their relevant daily dietary intake, which is in the same order of magnitude of that reported for the dietary fibre. In particular coffee melanoidins, which are mainly constituted by polysaccharides quite similar to those constituting the classical soluble dietary fibre, could represent a significant part of the whole intake of soluble dietary fibre. An interesting parallel can be performed about the physiological functions of coffee melanoidins possessing a high antioxidant capacity due to the presence of chlorogenic acid fragments and cereal dietary fibre which is rich of phenolic compounds64 and increase the intake of antioxidants. 65

On the other hand, the enzyme-solubilised fraction of bread melanoidins is mainly made up of crosslinked protein and starch, a material quite different from dietary fibre. The evidence about the biological properties of this material are scarce and somehow contradictory; in any case the presence of a relevant moiety of proteins in the material reaching the lower gut is considered not beneficial.66,67

Finally, it should be remarked that although melanoidins from coffee and bread represent the major part of melanoidins intake in Western diets, other sources of melanoidins mentioned in the introduction can give a relevant contribution. In some cases the alternative source can even be predominant for peculiar dietary regimen. Considering an estimated daily intake close to $10 \mathrm{~g}$ per day (from all the possible sources) and the several different biological actions described for melanoidins, it is time to gain more insights in the biological functions of these compounds.

\section{Acknowledgements}

This research was partly supported by Scientific Research program from Comunidad de Madrid (ANALISYC-II Program S2009/AGR - I464).

\section{References}

I F. J.Morales, Food Chem., 2002, 76, 363.

2 E. K. Bekedam, H. A. Schols, M. A. J. S. van Boekel and G. Smith, J. Agric. Food Chem., 2006, 54, 7658.

3 H. Kato and H. Tsuchida, Prog. Food Nutr. Sci., I98I, 5, 147.

4 T. Hofmann, Eur. Food Res. Technol., 1998, 206, 251.

5 B. Cammerer and L. W. Kroh, Food Chem., 1995, 53, 55.

6 F. M. Nunes and M. Coimbra, J. Agric. Food Chem., 2007, 55, 3967.

7 T. Hofmann, J. Agric. Food Chem., 1998, 46, 389I.

8 R. Tressl, G. T. Wondrak, L. A. Garbe, R. P. Kruger and D. Rewicki, J. Agric. Food Chem., 1998, 46, 1765.

9 T. Hofmann, W. Bors and K. Stettmaier, J. Agric. Food Chem., 1999, 47, 391. 
I0 T. D. Obretenov, M. J. Kuntcheva, S. C. Mantchev and G. D. Valkova, J. Food Biochem., I99I, I5, 279.

II B. L. Milic, B. Grujic-Injac, M. V. Piletic, S. Lajgic and L. A. Kolarov, J. Agric. Food Chem., 1975, 23, 960.

12 R. J. Kuntcheva and T. D. Obretenov, Zeitschrift für Lebensmittel-Untersuchung und -Forschung, 1996, 202, 238.

I3 R. Ponnampalam and N. I. Mondy, J. Food Sci., 2006, 48, I6I3.

I4 O. Ac,ar, V. Gökmen, N. Pellegrini and V. Fogliano, Eur. Food Res. Technol., 2009, 229, 96 I.

I5 T. D. Obretenov, S. D. Ivanova, M. J. Kuntcheva and G. T. Somov, J. Agric. Food Chem., 1993, 4I, 653.

I6 H. Sakurai, H. Hashiba and A. Okuhara, J. Agric. Chem. Soc. Japan, I98I, 55, 7.

17 P. Giudici, M. Gullo, L. Solieri and P. M. Falcone, Adv. Food Nutr. Res., 2009, 58, 137.

I8 M. Ortega-Heras and M. L. Gonzalez-Sanjose, Food Sci. Technol., 2009, 42, 1729.

19 A. Adams, R. C. Borrelli, V. Fogliano and N. De Kimpe, J. Agric. Food Chem., 2005, 53, 4I 36.

20 V. Fogliano, S. M. Monti, T. Musella, G. Randazzo and A. Ritieni, Food Chem., 1999, 66, 293.

2I H. G. Maier, W. Dietmair and J. Ganssman, Zeitschrift für Lebensmittel-Untersuchung und Forschung, 1968, 137, 282.

22 F. M. Nunes, A. Reis, M. R. M. Domingues and M. A. Coimbra, J. Agric. Food Chem., 2006, 54, 3428.

23 H. E. Maier and H. Buttle, Zeitschrift für Lebensmittel-Untersuchung und -Forschung, I973, I50, 33 I.

24 P. Montavon, A. F. Mauron and E. Duruz, J. Agric. Food Chem., 2003, 5I, 2335.

25 L. Henrich and W. Baltes, Zeitschrift für Lebensmittel-Untersuchung und -Forschung, I962, I85, 366.

26 M. Takenaka, N. Sato, H. Asakawa, X. Wen, M. Murata and S. Homma, Biosci., Biotechnol., Biochem., 2005, 69, 26.

27 N. Terasawa, M. Murata and S. Homma, J. Food Sci., 1996, 6I, 669.

28 R. C. Borrelli, A. Visconti, C. Mennella, M. Anese and V. Fogliano, J. Agric. Food Chem., 2002, 50, 6527.

29 A. D’Agostina, G. Boschin, F. Bacchini and A. Arnoldi, J. Agric. Food Chem., 2004, 52, 7 I I8.

30 A. Illy, and R. Viani, Espresso Coffee. The Chemistry of Quality; Academic Press, 1995, London.

3 I C. Delgado-Andrade and F. J. Morales, J. Agric. Food Chem., 2005, 53, 1403.

32 M. Lindenmeier, V. Faist and T. Hofmann, J. Agric. Food Chem., 2002, 50, 6997.

33 R. C. Borrelli and V. Fogliano, Mol. Nutr. Food Res., 2005, 49, 673.

34 T. Hofmann and P. Schieberle, J. Agric. Food Chem., 2002, 50, 319. 
35 L. Goya, C. Delgado-Andrade, J. A. Rufi an-Henares, L. Bravo and F. J. Morales, Mol. Nutr. Food Res., 2007, $51,536$.

36 F. J. Morales, C. Fernandez-Fraguas and S. Jimenez-Perez, Food Chem., 2005, 90, 82 I.

37 J. A. Rufian-Henares and F. J. Morales, Food Chem., 2008, II I, 1069.

38 S. Hiramoto, K. Itoh, S. Shizuuchi, Y. Kawachi, Y. Morishita, M. Nagase, Y. Suzuki, Y. Nobuta, Y. Sudou, O. Nakamura, I. Kagaya, H. Goshima, Y. Kodama, F. C. Icatro, W. Koizumi, K. Saigenji, S. Miura, T. Sugiyama and N. Kimura, Helicobacter, 2004, 9, 429.

39 V. Somoza, Mol. Nutr. Food Res., 2005, 49, 663.

40 J. M. Ames, A. Wynne, A. Hofmann, S. Plos and G. R. Gibson, Br. J. Nutr., 1999, 82, 489.

4 I C. Dell'Aquila, J. M. Ames, G. R. Gibson and A. G. Wynne, Eur. Food Res. Technol., 2003, $217,382$.

42 D. Gniechwitz, N. Reichardt, E. Meiss, J. Ralph, H. Steinhart, M. Blaut and M. Bunzel, J. Agric. Food Chem., 2008, 56, 5960.

43 C. Alexander, Food Eng. Ingredients, 2007, 32, 18.

44 J. Díaz-Rubio and F. Saura-Calixto, J. Agric. Food Chem., 2007, 55, 1999.

45 V. Gökmen, A. Serpen and V. Fogliano, Trends Food Sci. Technol., 2009, 20, 278.

46 C. L. Vecchia and A. Taviani, Eur. J. Cancer Prev., 2007, 16, 385.

47 R. C. Borrelli, F. Esposito, A. Napolitano, A. Ritieni and V. Fogliano, J. Agric. Food Chem., 2004, 52, 1338.

48 D. Gniechwitz, N. Reichardt, M. Blaut, H. Steinhart and M. Bunzel, J. Agric. Food Chem., 2007, 55, 6989.

49 M. Garsetti, N. Pellegrini, C. Baggio and F. Brighenti, Br. J. Nutr., 2000, 84, 705.

50 I. Sanchez-Gonzalez, A. Jimenez-Escrig and F. Saura-Calixto, Food Chem., 2005, 90, 133.

5I M. A. Martın, S. Ramos, R. Mateos, J. A. Rufian-Henares, F. J. Morales, L. Bravo and L. Goya, J. Agric. Food Chem., 2009, 57, 7250.

52 Federacion Española del Café (FEC) (2009) Información estadística sectorial 2008, Seville, Spain.

53 COST. (1998) Melanoidins in Food and Health; COST Action 919; European Union, Brussels, Belgium.

54 S. I. F. Martins and M. A. J. S. Van Boekel, Food Chem., 2003, 83, 135.

55 T. Hofmann, In: Melanoidins in food and health - Cost Action 919 Berlin, Germany and Prague, Czech Republic, 2000, pp. I-2I.

56 A. D’Amicis, C. Scaccini, G. Tomassi, M. Anaclerio, R. Stornelli and A. Bernini, Int. J. Epidemiol., 1996, $25,513$.

57 International Coffee Organisation (ICO) (2009) Database 2009. London, England. http://www.ico.org/. 
58 R. C. Borrelli, C. Mennella, F. Barba, M. Russo, G. L. Russo, K. Krome, H. Erbersdobler, V. Faist and V. Fogliano, Food Chem. Toxicol., 2003, 4I, 1367.

59 S. Gonzalez-Mateo, M. L. Gonzalez-Sanjose and P. Muñiz, Food Chem. Toxicol., 2009, 47, 2798.

60 B. Spencer, British. Baker, 1974, 176, 19.

6I C. Leclercq, D. Arcella, R. Piccinelli, S. Sette, C. Le Donne and

A. Turrini, Public Health Nutrition, 2009, I-29, DOI: 10.10I7/SI368980009005035.

62 MAPA. Ministerio de Agricultura, Pesca y Alimentación, 2009, Madrid, Spain.

63 V. Faist and H. F. Erbersdobler, Ann. Nutr. Metab., 200I, 45, I.

64 P. Vitaglione, A. Napolitano and V. Fogliano, Trends Food Sci. Technol., 2008, 19, 45 I.

65 R. Pulido, M. Hernandez-Garcia and F. Saura-Calixto, European Journal of Clinical Nutrition, 2003, 57, 1275.

66 K. M. Tuohy, D. J. S. Hinton, S. Davies, M. J. C. Crabbe, G. R. Gibson and J. Ames, Mol. Nutr. Food Res., 2006, 50, 847.

67 D. J. S. Mills, K. Tuohy, J. Booth, M. Buck, M. J. C. Crabbe, G. R. Gibson and J. M. Ames, J. Appl. Microbiol., 2008, 105, 706. 
FIGURES AND TABLES

Table I Extraction yield ( $w / w)$ of roasted coffee as function of the procedure to prepare the coffee brew

\begin{tabular}{lll}
\hline & Coffee/water ratio & Soluble Fraction (\%) \\
\hline Espresso & 0.171 & 31.7 \\
Filter & 0.081 & 30.9 \\
Italian & 0.080 & 28.8 \\
Soluble & 0.020 & 95.0 \\
\hline
\end{tabular}

Table 2 Literature survey reporting the amount of melanoidins calculated for filter coffee brew preparations

\begin{tabular}{lllll}
\hline Procedure $^{a}$ & $\begin{array}{l}\text { Coffee : water } \\
\text { ratio }\end{array}$ & $\begin{array}{l}\text { Melanoidins }^{b} \\
\mathrm{~g} \mathrm{~kg}^{-1}\end{array}$ & $\begin{array}{l}\text { Melanoidins }^{c} \\
\text { g per 100 mL }\end{array}$ & Reference \\
\hline GF & 0.070 & 70 & 0.49 & 28 \\
GF & 0.050 & 53 & 0.25 & 34 \\
Dialysis & 0.070 & 51 & 0.39 & 36 \\
UF-T & 0.070 & 36 & 0.25 & 2 \\
Dialysis & 0.050 & 76 & 0.38 & 6 \\
UF-C & 0.070 & 81 & 0.57 & 37 \\
UF-C & 0.070 & 115 & 0.81 & 31 \\
UF-T & 0.050 & 90 & 0.45 & 42
\end{tabular}

${ }^{a}$ Procedure for melanoidin isolation. ${ }^{b}$ Melanoidin content per $\mathrm{kg}$ of roasted coffee powder. ${ }^{c}$ Melanoidin content per $100 \mathrm{~mL}$ of coffee brew.Gel-filtration (GF), ultrafiltration-tangential (UF-T), ultrafiltration-centrifugation (UF-C).

Table 3 Estimated melanoidins content per serving size for different preparations of coffee brew

\begin{tabular}{lllll}
\hline $\begin{array}{l}\text { Coffee Brew } \\
\text { preparation }\end{array}$ & $\begin{array}{l}\text { Melanoidins } \\
\text { g per } 100 \mathrm{~g} \text { coffee }\end{array}$ & $\begin{array}{l}\text { Serving } \\
\text { size } \mathrm{mL}\end{array}$ & $\begin{array}{l}\text { Coffee : water } \\
\text { ratio }\end{array}$ & $\begin{array}{l}\text { Amount } \\
\text { serving mg }\end{array}$ \\
\hline Espresso & 7.2 & 50 & 0.031 & 111.6 \\
Filter & 7.2 & 130 & 0.025 & 233.9 \\
Italian & 7.2 & 60 & 0.023 & 99.3 \\
Soluble & 22.8 & 100 & 0.019 & 433.2 \\
\hline
\end{tabular}


Table 4 Estimation of the dietary intake of coffee melanoidins (CM) in different world regions for different scenarios

\begin{tabular}{llll}
\hline World region & $\begin{array}{l}\text { mg CM per } \\
\text { day per capita }^{a}\end{array}$ & $\begin{array}{l}\text { mg CM per } \\
\text { day per capita }\end{array}$ & $\begin{array}{l}\text { mg CM per } \\
\text { day per capita }^{c}\end{array}$ \\
\hline Europe & 596.3 & 1192.6 & 2683.4 \\
North America & 695.7 & 1391.4 & 3130.6 \\
Central America & 231.9 & 463.8 & 1043.5 \\
South America & 513.5 & 1027.1 & 2310.7 \\
Asia & 49.7 & 99.4 & 223.6 \\
Middle-East/North & 115.9 & 231.9 & 521.8 \\
$\quad$ Africa & & 99.4 & 223.6 \\
$\begin{array}{l}\text { Sub-Sahara Africa } \\
\text { Oceania }\end{array}$ & 49.7 & 762.0 & 1714.4 \\
${ }^{a}$ All population is considered as coffee drinkers. ${ }^{b}$ Half population as \\
coffee drinkers. ${ }^{c}$ At 95th percentile. \\
\hline
\end{tabular}

Table 5 Percentage of the crust on the total weight and amount of melanoidins measured in different type of bread and in dry biscuits

\begin{tabular}{lll}
\hline Product type & $\begin{array}{l}\text { Percentage } \\
\text { of }^{\text {crust }}{ }^{a}\end{array}$ & $\begin{array}{l}\text { Amount of melanoidins } \\
\text { (g per 100g of crust) }\end{array}$ \\
\hline $\begin{array}{l}\text { Sourdough loaves } \\
\text { Sliced bread }\end{array}$ & $20 \pm 1$ & $30 \pm 2$ \\
Baguette & $9 \pm 1$ & $18 \pm 1$ \\
Dry biscuits & $35 \pm 2$ & $14 \pm 2$ \\
${ }^{a}$ Standard deviation refers to 3 measures performed on the same bread \\
type. \\
\hline
\end{tabular}

Table 6 Dietary intake of melanoidins (g per person per day) from bread and biscuits. Values were calculated considering the content of melanoidins and the percentage of crusts as reported in Table 5 and the bread and biscuits consumption for average and 95 th percentile, respectively

\begin{tabular}{lll}
\hline Product type & $\begin{array}{l}\text { Melanoidins } \\
\text { intake (Average) }\end{array}$ & $\begin{array}{l}\text { Melanoidins } \\
\text { intake (95th) }\end{array}$ \\
\hline $\begin{array}{l}\text { Sourdough } \\
\text { loaves }\end{array}$ & $6.7 \pm 0.4$ & $15.0 \pm 1.0$ \\
$\begin{array}{l}\text { Sliced bread } \\
\text { Baguette }\end{array}$ & $1.8 \pm 0.1$ & $4.1 \pm 0.3$ \\
Dry biscuits & $5.5 \pm 0.3$ & $12.3 \pm 0.7$ \\
\hline
\end{tabular}


Fig. I Estimation of the dietary intake of coffee melanoidins as distributed by countries. Black bars represent average values for European Union, United Estates of America and Japan for reference.

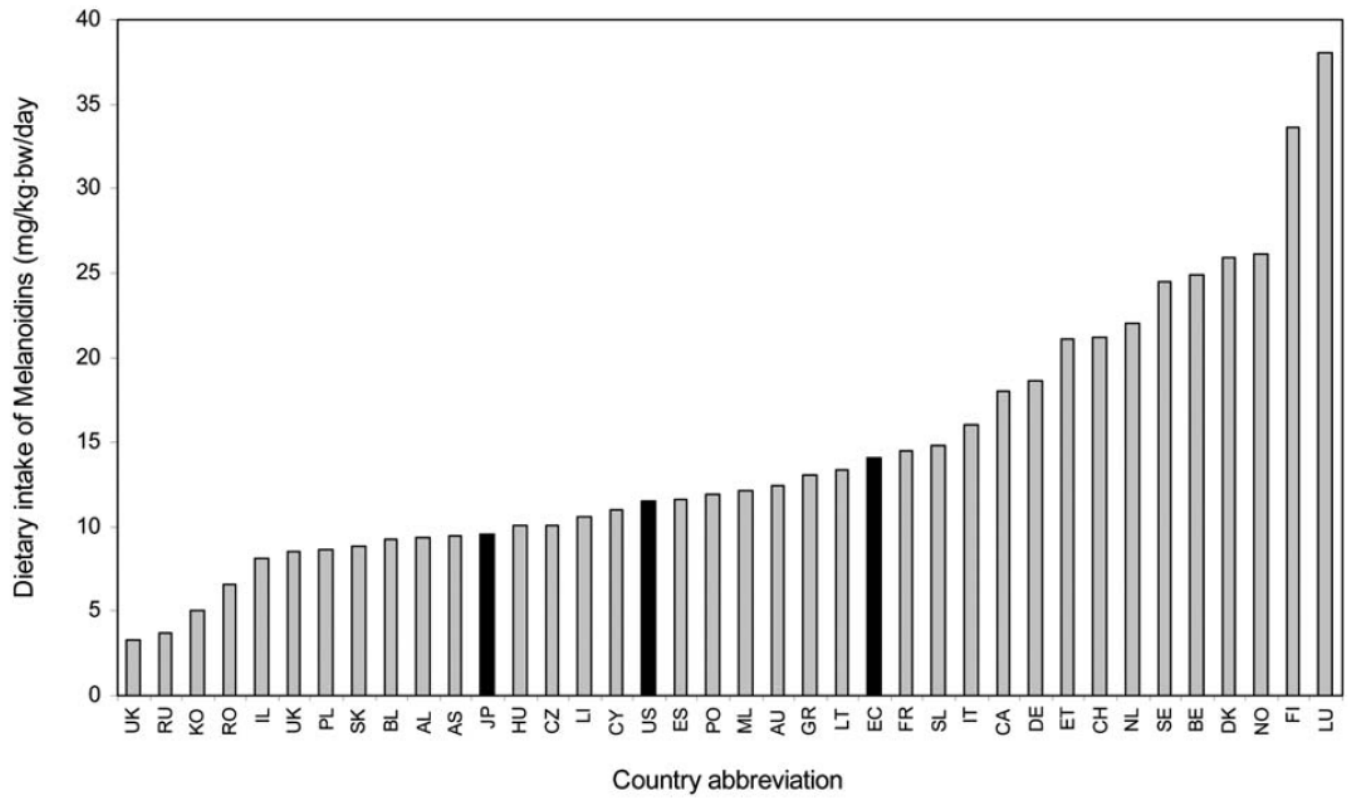

